\title{
Phase angle cutoff value as a marker of the health status and functional capacity in breast cancer survivors
}

\author{
Alexandre D. Martins ${ }^{\text {a,b, }}$, Rafael Oliveira ${ }^{\text {a,b,c }}$, João Paulo Brito ${ }^{\text {a,b,c }}$, Tiago Costa ${ }^{\text {, }}$ \\ Fátima Ramalho ${ }^{\mathrm{a}, \mathrm{d}}$, Nuno Pimenta ${ }^{\mathrm{a}, \mathrm{d}}$, Rita Santos-Rocha ${ }^{\mathrm{a}, \mathrm{d}}$ \\ ${ }^{a}$ Sports Science School of Rio Maior - Polytechnic Institute of Santarém, Rio Maior, Portugal \\ ${ }^{\mathrm{b}}$ CIEQV - Life Quality Research Centre, Rio Maior, Portugal \\ ${ }^{\mathrm{c}}$ CIDESD - Research Centre in Sport Sciences, Health Sciences and Human Development, Vila Real, Portugal \\ ${ }^{\mathrm{d}}$ CIPER - Interdisciplinary Centre for the Study of Human Performance, Faculty of Human Kinetics (FMH), University of Lisbon, Cruz Quebrada, Portugal
}

\section{A R T I C L E I N F O}

\section{Keywords:}

Cancer patients

Bioimpedance

Hydration

Functional tests

\begin{abstract}
A B S T R A C T
Accurate predictive tools are key factors for cancer care. Phase angle (PhA) has been proposed as a marker of cellular health, particularly of cell-membrane integrity. Cutoff values have been proposed, including for cancer survivors. This study aimed to assess the usefulness of the proposed PhA cutoff, as a marker of bioelectrical impedance analysis (BIA) assessed health-status, and functional capacity in breast cancer (BC) survivors. This cross-sectional study included 25 women $(50.6 \pm 8.6$ yrs) survivors of $\mathrm{BC}$, divided into two groups according to the PhA reference value of $5.6^{\circ}$ (group 1 [G1]: $\mathrm{PhA} \leq 5.6^{\circ}$ [ $\left.\mathrm{n}=13\right]$; group 2 [G2]: $\mathrm{PhA}>5.6^{\circ}$ [n=12]) (Gupta et al. 2008). BIA-assessed health status parameters included: extracellular water (ECW), intracellular water (ICW), total body water (TBW), PhA, body mass, fat-free mass, muscle mass, body cell mass (BCM). Four functional tests were performed: $30 \mathrm{~s}$ chair-stand test, timed up and go test, ball throw test and 6-minute walking test. Results showed G2 had lower ECW/ICW ratio $(\mathrm{p}=0.001 ; \mathrm{ES}=1.2)$, ECW/BCM ratio $(\mathrm{p}=0.001 ; \mathrm{ES}=3.2)$ and $\mathrm{ECW} / \mathrm{TBW}$ ratio $(\mathrm{p}=0.001 ; \mathrm{ES}=4.8$ ). There was no difference in functional capacity between groups. The results of the present study show that patients with higher PhA values have a higher ICW values and preservation in the ECW/ICW ratio, suggesting it's a better cell membrane quality and integrity. Relation of both PhA and cell membrane integrity with functional capacity warrants further research.
\end{abstract}

\section{Introduction}

Some of the most common side effects of both the disease and related treatments in cancer survivors include: fatigue, loss of appetite, nausea, pain, weight loss, loss of muscle mass, changes in the integrity of the cell membrane, and changes in the balance of body fluids [1], mainly in advanced stages [2], which contribute to morbidity and mortality [3]. Body composition assessment is an important tool to assess health status of cancer survivors [4].

In this sense, bioelectrical impedance analysis (BIA) has been found useful for cancer survivors [1] and provides information on patients' body composition and nutritional status, such as muscle mass and fluid status (balance of body water compartments) [5-7].

BIA analysis is an easy-to-use, non-invasive method that measures the electrical properties of the patient's tissues and has been used for many years to assess body composition including fat-free mass $[6,8,9]$.
Previous studies have found that patients with a high fat-free mass index (FFMI) (calculated from fat-free mass/weight) had a significantly better prognosis than did patients with a low FFMI [9-11]. Recently, it has been used for clinical assessment of the phase angle (PhA) [8-11], extracellular water (ECW), intracellular water (ICW) [10,12], body cell mass (BCM) $[12,13]$ and different compartments ratios [4,14]. The PhA is a non-invasive simple measure directly retrieved from resistance (R) and reactance (Xc) raw data [9-11], which appears to be even more interesting for cancer survival $[9,11,15]$. From a biophysical point of view, $\mathrm{PhA}$ is calculated from the arctangent of the ratio between the $\mathrm{R}$ and Xc, where R arises from ECW and ICW distribution, and, conversely, Xc arises from the cell membrane's ability to take an electric load and liberate it at a later moment, after a brief delay $[7,8,16]$. BCM is highly clinically relevant as it is defined as the total mass of all metabolically active, living, and functional cellular elements [12,13]. Loss of BCM can cause decreased functional capacity and immunological function [17].

\footnotetext{
* Corresponding author.

E-mail address: af_martins17@hotmail.com (A.D. Martins).
} 
Commonly used ratios include the determination of the ECW/ICW ratio that allows for the identification of changes in the PhA [18-20]. Changes in PhA observed in cancer survivors may be attributed to the disease or related treatments [21,22]. A decrease in ICW, which also reflects a loss of BCM, is often accompanied by an accumulation of ECW $[17,21,23]$. Another relevant clinical indicator is the ECW/Total Body Water (TBW) ratio, which has been recognized as an indicator of edema [7]. Edema formation therefore results from fluid redistribution between ECW and ICW spaces and can compromise cell function [11]. An ECW/ICW ratio greater than 0.4 has been suggested for early detecting the onset of lymphedema [24].

Miura et al. [25] assessed ECW/TBW in survivors from different types of cancer found higher prevalence of edema in patients with a PhA below $5^{\circ}$, thus reporting a strong association between these two parameters. Additionally, during radiotherapy treatments, ECW/TBW ratio values have been reported to increase [26].

A higher PhA value is positively associated with a higher capacitance of cell membranes $[10,16]$, while reduced $\mathrm{PhA}$ values suggest a deterioration and can compromise all cell functions, namely poor integrity and a high risk of cell apoptosis $[9,16,27]$. Several studies have shown that a reduced $\mathrm{PhA}$ can indicate a reduced life expectancy in several types of cancer, such as, breast cancer (BC) [11], and in survivors of other types of advanced cancer [11,15,21].

Although clinical studies using these parameters have been previously conducted, the present study emerged from the need to increase the robustness of the PhA cutoff values standardization $[8,28]$. This study aimed at exploring the usefulness of proposed phase angle cutoff [11], as a marker of BIA assessed health-status, and functional capacity in $\mathrm{BC}$ survivors.

\section{Methods}

\subsection{Participants and study design}

The present study included 25 women (50.6 \pm 8.6 yrs) survivors of BC. Participants were divided into two groups according to the $\mathrm{PhA}$ reference value of $5.6^{\circ}[11]$. Group 1 (G1) was classified as those with a $\mathrm{PhA} \leq 5.6^{\circ}(\mathrm{n}=13)$, and group 2 (G2) was classified as those with a PhA $>5.6^{\circ}(\mathrm{n}=12)$. The mean ( \pm standard deviation) values for height, weight, and age for G1 was $1.6 \pm 0.6 \mathrm{~m}, 66.8 \pm 10.1 \mathrm{~kg}$, and $50.5 \pm 8.6$ years, respectively, and those for G2 were $1.5 \pm 0.6 \mathrm{~m}, 67.5 \pm 14.8 \mathrm{~kg}$, and $51.1 \pm 8.9$ years, respectively.

All participants were volunteers and were being followed up in different hospitals in the Lisbon region, Portugal. After eligibility assessment and clearance from their oncologist, individuals were contacted to schedule a face-to-face interview, to confirm the data. Before providing written informed consent to participate, each participant was informed about the study's goals and potential benefits. The ethics committee of the Polytechnic Institute of Santarém approved the study (approval number: 042020) in accordance with the World Medical Association's Declaration of Helsinki for human studies [29].

The inclusion criteria were as follows: $i$ ) women aged between 30 and 69 years; ii) primary diagnosis of BC confirmed by biopsy (stage I to IIIa); iii) no history of surgical or non-surgical treatment before the cancer diagnosis; and iv) not pregnant. The exclusion criteria were as follows: i) presence of active metastases; ii) presence of tumours; iii) presence of cardiovascular problems (e.g., heart failure before tumor diagnosis); and $i v$ ) presence of other diseases (e.g., diabetes, hypertension, depression).

\subsection{Procedures}

After consent, information about age, type of tumor, treatments performed, year of tumor diagnosis, current medication, type of surgery and tumor stage were recorded. The evaluations were carried out in the morning, in a clinical facility with an ambient temperature and relative humidity of $22-23{ }^{\circ} \mathrm{C}$ and $50-60 \%$, respectively. The measurements were performed after a minimum of 8 hours of fasting and after emptying the bladder. Participants were asked not to exercise nor ingest caffeine or alcohol during the 12 hours prior to the assessment. All evaluations were performed by the same researchers in order to minimize possible measurement errors [30].

\subsubsection{Anthropometric assessment}

On their first visit to the laboratory, participants' weight and height were measured following standard procedures [31], using a scale and stadiometer (SECA 220, Germany, Hamburg), to the nearest $0.01 \mathrm{~kg}$ and $0.1 \mathrm{~cm}$, respectively. Body mass index (BMI) was calculated using the standard formula $\left(\mathrm{BMI}=\right.$ body mass $[\mathrm{kg}] /$ height $\left.^{2}[\mathrm{~m}]\right)$.

\subsubsection{Bioelectrical impedance analysis assessment}

All participants underwent BIA assessment using multifrequency tetrapolar InBody S10 equipment (Model JMW140, Biospace Co, Ltd, Seoul, Korea), following manufacturer's and comprehensive guidelines $[32,33]$. All metallic objects that were in contact with the skin were removed, the skin was cleaned with ethyl alcohol and hydrophilic cotton at the eight electrode placement sites, and the patients remained in the supine position in a space without noise for 10 minutes. Then, eight electrodes are placed in eight tactile points (thumbs, middle fingers and ankles of both hands and feet, respectively) to assess multi segmental frequency analysis. According to the manufactural instructions, InBody analysis is highly accurate because the measured value of a certain part does not affect the measurements of other segments. InBody presents technology of segmental analysis and thus, it can exactly figure out difference by gender, aging, disease and ethnic without any empirical estimation. A total of 30 impedance measurements are obtained using 6 different frequencies $(1,5,50,250,500$ and $1000 \mathrm{kHz})$ at the five following segments of the body: right and left arms, trunk, right and left legs). In addition, 15 reactance, $\mathrm{PhA}$ measurements by using three different frequencies $(5,50,250 \mathrm{kHz})$ at the five following segments (right and left arms, trunk, right and left legs) [32,33].

The following parameters were assessed: TBW, in litres (L); ECW (L); ICW (L), fat mass (FM), in kilograms (kg); fat-free mass (FFM) (kg); muscle mass (MM) (kg); BCM (kg); and the ECW/TBW ratio. Afterward, the ECW/ICW ratio and the ECW/BCM ratio were calculated. PhA (50 $\mathrm{kHz}$ ), in degrees $\left({ }^{\circ}\right)$ was also assessed but only data referring to $50 \mathrm{kHz}$ was reported [7,33,34].

\subsubsection{Functional capacity tests}

The assessment of functional capacity was conducted using standardized tests often used in breast cancer survivors [35,36], including: 30 s chair-stand test [37,38]; Timed Up and Go Test (TUG) [39]; Ball Throw Test (3 kg) [40]; and 6-minute walking test [41,42].

\subsection{Statistical analysis}

In the present study data was analysed using the Statistical Package for the Social Sciences version 23.0 (IBM-SPSS software, SPSS Inc., Chicago, IL, USA). Descriptive statistics (mean \pm standard deviation or percentage) were used, and both normality and homogeneity were verified for all variables using Shapiro-Wilk test and Levene test, respectively. To analyze differences between groups, $t$ test for independent samples was performed. When differences were found, the effect size (ES) was calculated to determine the magnitude of the effects through the standardization of the coefficients according to the standard deviation between subjects, and the following criteria were used: $\langle 0.2$, reduced effect; 0.2-0.6, small effect; 0.6-1.2, moderate effect; $1.2-2.0$, large effect; and $>2.0$, very large effect [43].

The relationship between continuous variables in each of the groups was also verified using the Pearson product-moment correlation coefficient $(r)$, thus determining the magnitudes of the associations $(r=0.10-0.29$ : small; $r=0.30-0.49$ : moderate; $r=0.50-1.0$ : strong) [44]. 
The significance level considered for all tests was $\mathrm{p} \leq 0.05$.

\section{Results}

\subsection{General features}

The main characteristics of BC survivors included in this study are shown in Table 1. There were no significant differences found between the groups for the referred variables. Also, in G1 Pearson correlations were found for age with weight $(r=-0.614 ; \mathrm{p}=0.025)$; age with $\mathrm{BMI}(\mathrm{r}=-$ 0.668 ; $\mathrm{p}=0.013)$; weight with BMI $(\mathrm{r}=-0.648$; $\mathrm{p}<0.01)$; BMI with RHR $(r=0.559 ; p=0.047)$; SBP with DBP $(r=0.629 ; p=0.021)$; SBP with time after diagnosis $(\mathrm{r}=0.724 ; \mathrm{p}=0.005)$; and $\mathrm{DBP}$ with time after diagnosis $(\mathrm{r}=0.572 ; \mathrm{p}=0.041)$. In $\mathrm{G} 2$, Pearson correlations were found for age with time after diagnosis $(\mathrm{r}=0.950 ; \mathrm{p}<0.01)$; weight with $\mathrm{BMI}(\mathrm{r}=0.942$; $\mathrm{p}<0.01)$; and SBP with DBP $(\mathrm{r}=0.861 ; \mathrm{p}<0.01)$.

Clinical characteristics of both G1 and G2 participants are detailed in Table 2. All participants were submitted to surgery, and most benefited from additional therapy approaches including radiotherapy, chemotherapy, and hormone therapy either alone or combined. Participants who only underwent radiotherapy beside surgery could only be found in G2. Participants who benefited from hormonal therapy in G1 were twofold that of G2. Participants who benefited from the three types of treatment together, beside surgery, were more common in G1. Secondary lymphedema was not present in the majority of the participants from both groups. In the analysis of comparisons between the dichotomous variables Secondary Lymphedema and Surgery type of both G1 and G2 participants, no significant differences were found. In the remaining variables, it was not possible to make comparisons due to the low number of incidences of the factors and categories of the variables.

\subsection{Functional capacity tests}

Comparison between the results of functional tests obtain by both G1 and G2 can be found in Table 3. No differences were found in functional capacity between groups. In G2, there were no Pearson correlations, but in G1 they were registered, for $30 \mathrm{~s}$ chair-stand test with TUG $(\mathrm{r}=-0.651$; $\mathrm{p}=0.016)$ and TUG with ball throw test $(\mathrm{r}=-0.765 ; \mathrm{p}=0.020)$.

\subsection{Body composition analysis}

Significant differences were observed between the groups for some variables measured by BIA after performing the $t$-test for independent samples (Table 4). Results for ECW/ICW ratio were lower in G2, as compared with G1, with a large magnitude of effect. G2 had significantly

Table 1

General characteristics of the participants.

\begin{tabular}{llll}
\hline Variables & $\begin{array}{l}\mathrm{G} 1(\mathrm{n}=13) \\
\mathrm{PhA} \leq 5.6^{\circ}\end{array}$ & $\begin{array}{l}\mathrm{G} 2(\mathrm{n}=12) \\
\mathrm{PhA}>5.6^{\circ}\end{array}$ & $\mathrm{p}$ \\
\hline Age (years) & $50.5 \pm 8.6^{\mathrm{a}, \mathrm{b}}$ & $51.1 \pm 8.9^{\mathrm{e}}$ & .842 \\
Weight $(\mathrm{kg})$ & $66.8 \pm 10.1^{\mathrm{b}}$ & $67.5 \pm 14.8^{\mathrm{b}}$ & .888 \\
Height (m) & $1.6 \pm 0.6$ & $1.5 \pm 0.6$ & .0 .54 \\
$\mathrm{BMI}^{2}\left(\mathrm{~kg} / \mathrm{m}^{2}\right)$ & $25.5 \pm 3.9^{\mathrm{c}}$ & $27.3 \pm 5.6$ & .344 \\
$\mathrm{SpO}_{2}$ & $97.2 \pm 1.3$ & $97.1 \pm 1.6$ & .799 \\
$\mathrm{RHR}(\mathrm{bpm})$ & $70.9 \pm 8.9$ & $68.8 \pm 9.2$ & .569 \\
$\mathrm{SBP}(\mathrm{mmHg})$ & $117.4 \pm 13^{\mathrm{d}}$, e & $118.6 \pm 15.1^{\mathrm{d}}$ & .838 \\
$\mathrm{DBP}(\mathrm{mmHg})$ & $81.5 \pm 5.5^{\mathrm{e}}$ & $80.4 \pm 8.3$ & .711 \\
Time after diagnosis (years) & $6.2 \pm 5.5$ & $7.5 \pm 5.9$ & .585 \\
Tumor size (mm) & $19.9 \pm 13.5$ & $27.8 \pm 15.6$ & .182 \\
\hline
\end{tabular}

$\mathrm{BMI}=$ Body Mass Index; $\mathrm{SpO}_{2}=$ Oxygen Saturation level; $\mathrm{RHR}=$ Rest heart rate; $\mathrm{SBP}=$ Systolic Blood Pressure; $\mathrm{DBP}=$ Diastolic Blood Pressure

a Denotes correlation with weight

b Denotes correlation with BMI

c Denotes correlation with RHR

d Denotes correlation with DBP

e Denotes correlation with time after diagnosis; all $\mathrm{p} \leq 0.05$.
Table 2

Clinical characteristics of participants, $n(\%)$.

\begin{tabular}{lll}
\hline Variables & $\begin{array}{l}\mathrm{G} 1(\mathrm{n}=13) \\
\mathrm{PhA} \leq 5.6^{\circ}\end{array}$ & $\begin{array}{l}\mathrm{G} 2(\mathrm{n}=12) \\
\mathrm{PhA}>5.6^{\circ}\end{array}$ \\
\hline Treatments & & \\
Surgery & $13(100)$ & $12(100)$ \\
Radiotherapy & $0(0)$ & $2(16.7)$ \\
Chemotherapy & $2(15.4)$ & $3(25)$ \\
Hormonal Therapy & $0(0)$ & $1(8.3)$ \\
Radiotherapy + Chemotherapy & $3(23.1)$ & $3(25)$ \\
Radiotherapy + Chemotherapy + Hormone Therapy & $8(61.5)$ & $3(25)$ \\
Surgery type & & \\
Mastectomy & $12(92.3)$ & $10(83.3)$ \\
Quadrantectomy & $1(7.7)$ & $2(16.7)$ \\
Hormonal Therapy & & \\
Aromatase Inhibitors & $2(15.4)$ & $2(16.7)$ \\
Tamoxifen & $5(38.5)$ & $2(16.7)$ \\
Aromatase + Tamoxifen Inhibitors & $1(7.7)$ & $0(0)$ \\
Did not perform & $5(38.5)$ & $8(66.7)$ \\
Tumor Stage & & \\
I & $2(15.4)$ & $6(50)$ \\
II & $7(53.8)$ & $4(33.3)$ \\
III & $3(23.1)$ & $2(16.7)$ \\
IV & $1(7.79)$ & $0(0)$ \\
Type of Breast Carcinoma & & \\
Ductal carcinoma in situ & $2(15.4)$ & $5(41.7)$ \\
Non-Special Invasive Type & $6(46.2)$ & $5(41.7)$ \\
Invasive Lobular Carcinoma & $4(30.8)$ & $2(16.7)$ \\
Invasive Papillary Carcinoma & $1(7.7)$ & $0(0)$ \\
Secondary Lymphedema & $5(38.5)$ & $3(25)$ \\
Yes & $8(61.5)$ & $9(75)$ \\
No & & \\
\hline & & \\
& &
\end{tabular}

Table 3

Results of functional capacity tests.

\begin{tabular}{llll}
\hline Functional capacity tests & $\begin{array}{l}\text { G1 }(\mathrm{n}=13) \\
\mathrm{PhA} \leq 5.6^{\circ}\end{array}$ & $\begin{array}{l}\mathrm{G} 2(\mathrm{n}=12) \\
\mathrm{PhA}>5.6^{\circ}\end{array}$ & $\mathrm{p}$ \\
\hline 30 s Chair-stand Test (reps) & $15.1 \pm 3.9^{\mathrm{a}}$ & $15.4 \pm 4.1$ & .835 \\
TUG (s) & $5.7 \pm 0.7^{\mathrm{b}}$ & $6.1 \pm 0.8$ & .264 \\
Ball Throw Test (m) & $1.8 \pm 0.7^{\mathrm{b}}$ & $1.9 \pm 0.5$ & .451 \\
6-min Walking Test (m) & $804.9 \pm 119.14$ & $787.9 \pm 76.2$ & .678 \\
\hline TUG=Time Up and Go & & & \\
a d Denotes correlation with TUG & & \\
b d Denotes correlation with Ball Throw Test; all $\mathrm{p} \leq 0.05$. &
\end{tabular}

lower ECW/BCM ratio values than G1 with a very large magnitude of effect. Similarly, the ECW/TBW ratio was significantly lower in G2 compared to G1, with a very large magnitude of effect. Results for the remaining body composition variables were not different between the groups.

Pearson correlations between $\mathrm{PhA}$ and body composition variables showed that $\mathrm{PhA}$ was correlated with all mentioned ratios in both groups (Fig. 1). In G1 PhA was correlated with ECW/ICW ratio $(\mathrm{r}=-0.569$; $\mathrm{p}=0.043)$; ECW/BCM ratio $(\mathrm{r}=-0.577 ; \mathrm{p}=0.039)$; and $\mathrm{ECW} / \mathrm{TBW}$ ratio $(\mathrm{r}=-0.636 ; \mathrm{p}=0.020)$. In $\mathrm{G} 2$, PhA was correlated with TBW $(\mathrm{r}=0.717$; $\mathrm{p}=0.009$ ); ICW ( $\mathrm{r}=0.731 ; \mathrm{p}=0.007)$; ECW ( $\mathrm{r}=0.694 ; \mathrm{p}=0.012)$; body lean mass $(\mathrm{r}=0.722 ; \mathrm{p}=0.008)$; muscle mass $(\mathrm{r}=0.731 ; \mathrm{p}=0.007)$; and $\operatorname{BCM}(r=0.732 ; \mathrm{p}=0.007)$.

\section{Discussion}

The present study aimed at assessing the usefulness of proposed phase angle cutoff, as a marker of bioelectrical impedance analysis (BIA) assessed health-status, and functional capacity in breast cancer (BC) survivors. Retrospective observational data on the studied topic has been considered scarce in the studied population $(8,28)$.

In this study PhA values of both G1 $\left(5.2^{\circ} \pm 0.26\right)$ and G2 $\left(5.9^{\circ} \pm 0.3\right)$ were found very low compared to the reference values for the apparently healthy population of $6.55^{\circ} \pm 0.87$ [45]. Current $\mathrm{PhA}$ results are, 
Table 4

Electrical bioimpedance parameters.

\begin{tabular}{lllll}
\hline Variables & $\begin{array}{l}\mathrm{G} 1(\mathrm{n}=13) \\
\mathrm{PhA} \leq 5.6^{\circ}\end{array}$ & $\begin{array}{l}\mathrm{G} 2(\mathrm{n}=12) \\
\mathrm{PhA}>5.6^{\circ}\end{array}$ & $\mathrm{p}$ & $\mathrm{ES}$ \\
\hline PhA ( $\left.{ }^{\circ}\right)$ & $5.2 \pm 0.26^{\mathrm{a}, \mathrm{b}, \mathrm{c}}$ & $5.9 \pm 0.3^{\mathrm{d}, \mathrm{e}, \mathrm{f}, \mathrm{g}, \mathrm{h}, \mathrm{i}}$ & .01 & 2.5 \\
TBW (L) & $31.7 \pm 3.5$ & $31.7 \pm 5.9$ & .994 & - \\
ICW (L) & $19.5 \pm 2.1$ & $19.7 \pm 3.6$ & .889 & - \\
ECW (L) & $12.2 \pm 1.4$ & $12.0 \pm 2.3$ & .840 & - \\
Body fat (kg) & $23.1 \pm 8.9$ & $25.5 \pm 10.5$ & .543 & - \\
Body lean mass (kg) & $43.2 \pm 4.9$ & $43.2 \pm 7.9$ & .999 & - \\
Muscle mass (kg) & $23.4 \pm 2.8$ & $23.6 \pm 4.7$ & .885 & - \\
BCM (kg) & $27.9 \pm 3.1$ & $28.1 \pm 5.2$ & .877 & - \\
ECW/ICW & $0.62 \pm 0.009$ & $0.61 \pm 0.008$ & .01 & 1.2 \\
ECW/BCM & $0.44 \pm 0.006$ & $0.42 \pm 0.006$ & .01 & 3.2 \\
ECW/TBW & $0.40 \pm 0.004$ & $0.37 \pm 0.004$ & .01 & 4.8 \\
\hline
\end{tabular}

$\mathrm{PhA}=$ Phase Angle; TBW=Total Body Water; ICW=Intracellular water; $\mathrm{BCM}=$ Body Cell Mass; $\left({ }^{\circ}\right)=$ degree; $\mathrm{L}=$ liter; $\mathrm{Kg}=$ kilogram

a Denotes correlation with ECW/ICW

b Denotes correlation with ECW/BCM

c Denotes correlation with ECW/TBW

d Denotes correlation with TBW

e Denotes correlation with ICW

f Denotes correlation with ECW

g Denotes correlation with body lean mass

h Denotes correlation with muscle mass

${ }^{\mathrm{i}}$ Denotes correlation with BCM; all $\mathrm{p} \leq 0.05$.

however, in line with previous research findings in similar populations $[8,9]$. Accordingly, the reference of $5.6^{\circ}$ has been proposed and validated to be used as a cutoff for PhA of BC survivors [11]. This cutoff has also been described as a health marker and predictor of survival in cancer patients [46], and was used in the present study to determine higher and lower PhA groups, G2 and G1, accordingly.

As a marker of cellular integrity, $\mathrm{PhA}$ is expected to be discriminant of health status and functional capacity. The PhA it is considered a marker of cellular function [47] as reflects in one hand, the capacitance behavior of tissues (reactance) and is associated with cell size and integrity of the cell membrane [11,27]. As a marker of cellular integrity [27], PhA is expected to be discriminant of health status and functional capacity. The present study confirms a better health status in participants with a higher PhA, as assessed by a significantly lower ECW/TBW ratio found these patients (G2) as opposed to patients with lower PhA (G1). The ratio between ECW and TBW has been acknowledged as an edema index [48] The study by Cho et al. [49] showed significant improvements in the ECW/TBW ratio in 29 female survivors of BC with secondary lymphedema after participating in a rehabilitation program (drainage massage, physical exercise, and use of elastic bands), with a significant difference between baseline and follow-up $(\mathrm{p}=0.043)$ found especially in the group with severe lymphedema ( $\mathrm{p}=0.007)$. A better ECW/TBW ratio results in a decrease in the edema state, which consists of a decrease in the ECW [50]. The fact that ECW/TBW has been found both modifiable and health-related, underlies this variable as an important management and intervention target in the studied population, and underscores the usefulness of $\mathrm{PhA}$ as a health status marker to be assessed in clinical practice.

Participants of group G2 seem to have superior cell quantity, quality, and vitality, expressed by the strong correlation between PhA and BCM $(\mathrm{r}=0.732 ; \mathrm{p}=0.007)$. Other studies have confirmed this finding, suggesting that PhA can be used as a predictor of cell quality and quantity of ICW [51]. Reductions in PhA may be explained by the reduction in fat-free mass and the increase in ECW, which expresses the state of cell hydration and the integrity of the cell wall [52]. Accordingly, Stefani et al. [12] found that after a 12-month aerobic and strength training program in 28 BC survivors, the PhA and BCM values increased significantly over the intervention period, whereas in the control group that did not exercise, there were no such results. Again, the modifiable and health-related nature of these variables underline their importance as management and intervention targets and underscore the usefulness of $\mathrm{PhA}$ as a health status marker to be assessed in clinical practice in the studied population.

In the present study, differences were found between the groups for ECW/ICW ratios $(\mathrm{p}=0.001 ; \mathrm{ES}=1.2)$. Ellis [53] reported that a $\mathrm{PhA}$
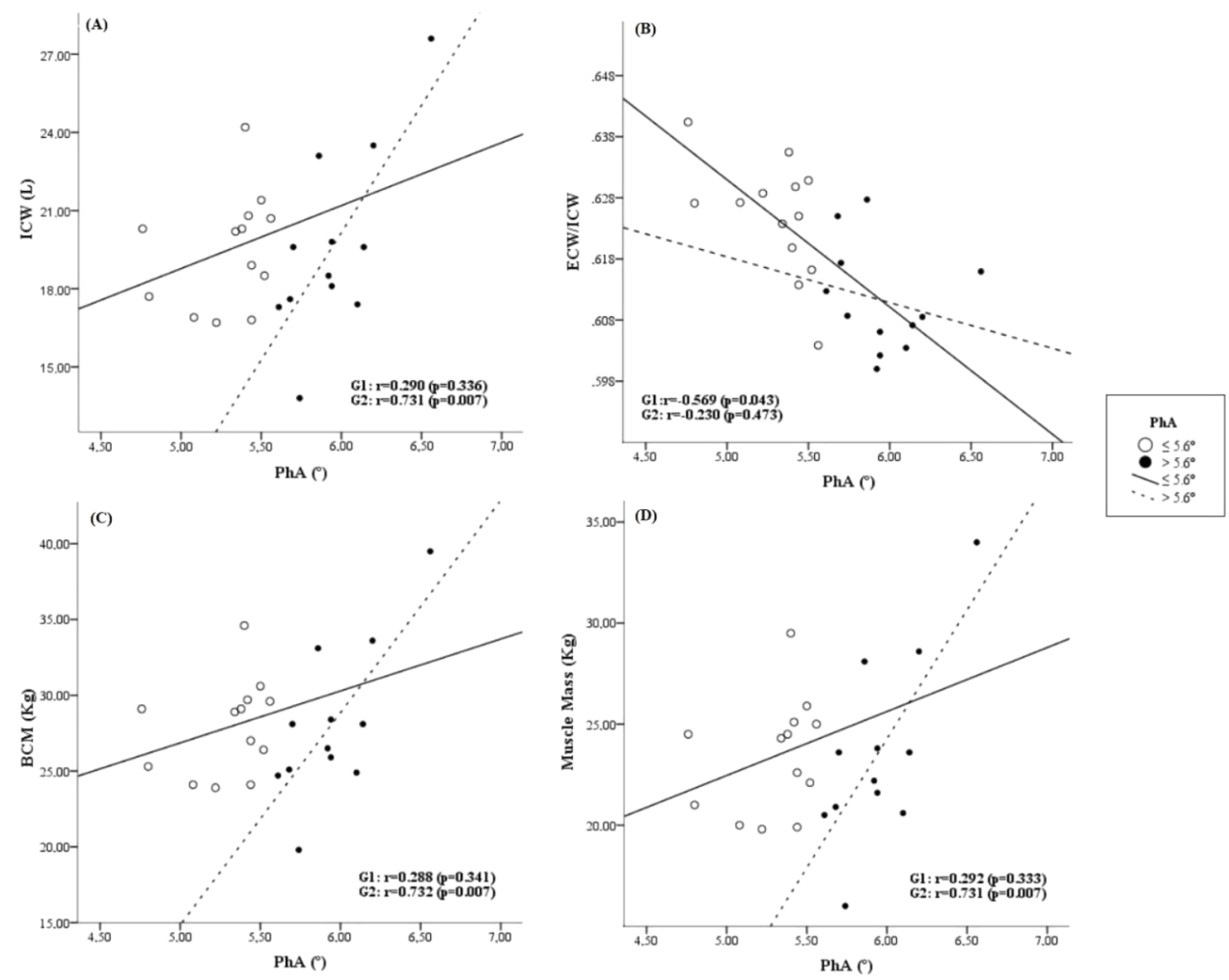

Fig. 1. Correlations between PhA and: (A) ICW; (B) ECW/ICW ratio; (C) BCM; (D) Muscle Mass. 
value below to $5^{\circ}$ can indicate a significant increase in ECW and a decrease in ICW. This seems to be the consequence of cell membranes integrity damage, leading to cell catabolism, particularly in cancer patients [2] and a decrease in life expectancy [21]. An explanation for these consequences may be that cancer and cancer treatment related catabolism causes a marked loss of intracellular fluid, and with this, a marked loss of muscle integrity [25]. The study by Nishiyama et al. [2] also registered differences in the ECW/ICW ratio $(\mathrm{p}=0.019)$, showing that a decrease in PhA reflects a loss in ICW, which causes an excessive movement of liquid into the extracellular space, leading to increased ECW/ICW ratio [54] and edema. The shift in water from the ICW to ECW compartments was suggested to mask the age-related atrophy in muscle mass, therefore leading to delayed identification of the need of intervention, as assessed by clinical approaches [55], resulting in increased risk and worse prognosis. The correlation found in G2 between the PhA and the ICW $(r=0.731 ; \mathrm{p}=0.007)$ was also found in a study by Yoon et al. [46] $(\mathrm{r}=0.98 ; \mathrm{p}<0.01)$, where male cancer survivors showed lower PhA values and lower ICW values than apparently healthy men, suggesting that this correlation may serve as a health marker and a predictor of survival $[4,47]$.

Regarding the ECW/BCM ratio, considered a marker of physical status [22], there is evidence that significant changes in the ECW/ICW ratio promote changes in the ECW/BCM ratio accompanied simultaneously by a reduction in the PhA [22]. The majority of cell mass is water so a reduction in intra-cellular water implies a reduction in cell mass. The results of the present study support these findings since the group with the lower PhA had higher ECW/BCM ratio values, with a significant difference between the groups ( $\mathrm{p}=0.001$; $\mathrm{ES}=3.2$ ). The authors Małecka-Massalska et al. [14] found that the ECW/BCM ratio values were significantly higher in 75 head and neck cancer survivors compared to the apparently healthy population $(r=-3.34 ; \mathrm{p}=0.008)$.

For the functional capacity tests, there were no significant differences between the groups. No association between functional capacity tests and the bioimpedance parameters of $\mathrm{PhA}$ was previously reported [56]. However, in G2, there was a strong correlation between the ball throw test and ICW $(r=0.691 ; p=0.013)$, a result that does not match the study by Reis [57], where no relationship between handgrip strength and water compartments were seen. However, the same study presented a correlation between the $\mathrm{PhA}$ and handgrip strength which supports the findings of Norman et al. [58]. Reductions in ICW have been found to reflect losses in $\mathrm{PhA}$, which may lead to decreases in strength [59], making it an important clinical parameter to consider [8]. However, no correlations were found between the functional capacity tests and overall water compartments [56], which warrants further research. The results of the present study and those presented by other studies $[8,57]$ underlie the need to monitor functional capacity of cancer survivors, particularly BC [60], from the moment of diagnosis to identify declines in physical capacity and to see if they are experiencing side effects of cancer treatments such as muscle weakness, mobility, and deficits in cardiorespiratory fitness, which may increase the risk of falls [61] and worsens the prognosis [62].

For future investigations, it is suggested to increase the sample size; although the variables studied in both groups met the criteria for normality, the number of patients in each group may not have allowed for significant differences in certain statistical techniques. In addition, more studies are required in order establish new $\mathrm{PhA}$ cut-off points or to reinforce the usefulness of cut-off point used in the present study. Also, it is recommended to include a handgrip strength assessment [8]. Moreover, the transversal nature of this study does not allow for the establishment of cause-effect relationships between variables.

\section{Conclusions}

In the present study, patients with a higher PhA had higher ICW and preservation of ECW/ICW ratio, which is suggestive of a better cell membrane quality and integrity. As has been shown, in BC and other types of cancer survivors, the present study supports $\mathrm{PhA}$ as a promising marker of the health status. Albeit different cancer types may need specific cutoffs, the present study suggests clinical relevance of reference value used for PhA in $\mathrm{BC}$ survivors. This study also encourages the use of functional tests in addition to $\mathrm{PhA}$, as this was not able to predict functional variations in these patients. In summary, this study endorses the use of BIA parameters and functional capacity testing to analyze health status of BC survivors.

\section{Funding}

This project was supported by the Portuguese Foundation for Science and Technology, I.P., Grant/Award Numbers UIDP/04748/2020, UIDB/ 04045/2020 and UIDP/04045/2020.

\section{Declaration of Competing Interest}

The authors declare no conflicts of interest.

\section{Acknowledgments}

The authors want to express their gratitude to the participants in this study for all their availability and help.

\section{References}

[1] N Sarhill, FA Mahmoud, R Christie, A. Tahir, Assessment of nutritional status and fluid deficits in advanced cancer, Am. J. Hosp. Palliat. Med. 20 (6) (2003) 465-473.

[2] VKG Nishiyama, SM Albertini, CMZG Moraes, MF de, Godoy, JG. de, Netinho, Malnutrition and clinical outcomes in surgical patients with colorectal disease, Arq. Gastroenterol. 55 (4) (2018) 397-402.

[3] RL Siegel, KD Miller, A. Jemal, Cancer statistics, 2019, CA Cancer J. Clin. 69 (1) (2019) 7-34.

[4] O Grundmann, SL Yoon, JJ. Williams, The value of bioelectrical impedance analysis and phase angle in the evaluation of malnutrition and quality of life in cancer patients - a comprehensive review, Eur. J. Clin. Nutr. 69 (12) (2015) 1290-1297.

[5] LC. Ward, Bioelectrical impedance analysis for body composition assessment: reflections on accuracy, clinical utility, and standardisation, Eur. J Clin. Nutr. 73 (2) (2019) 194-199.

[6] SY Lee, YJ Lee, J-H Yang, C-M Kim, W-S. Choi, The Association between Phase Angle of Bioelectrical Impedance Analysis and Survival Time in Advanced Cancer Patients: Preliminary Study, Korean J. Fam. Med. 35 (5) (2014) 251-256.

[7] U. Kyle, Bioelectrical impedance analysis? Part I: review of principles and methods, Clin. Nutr. 23 (5) (2004) 1226-1243.

[8] CN Matias, J Cavaco-Silva, M Reis, F Campa, S Toselli, L Sardinha, et al., Phase Angle as a Marker of Muscular Strength in Breast Cancer Survivors, Int. J. Environ. Res. Public Health 17 (12) (2020) 4452, 21 de Junho de.

[9] L Axelsson, E Silander, I Bosaeus, E. Hammerlid, Bioelectrical phase angle at diagnosis as a prognostic factor for survival in advanced head and neck cancer, Eur. Arch. Otorhinolaryngol 275 (9) (2018) 2379-2386.

[10] K Kohli, R Corns, K Vinnakota, P Steiner, C Elith, D Schellenberg, et al., A bioimpedance analysis of head-and-neck cancer patients undergoing radiotherapy, Curr. Oncol. 25 (3) (2018) e193-e199.

[11] D Gupta, CA Lammersfeld, PG Vashi, J King, SL Dahlk, JF Grutsch, et al., Bioelectrical impedance phase angle as a prognostic indicator in breast cancer, BMC Cancer 8 (1) (2008).

[12] L Stefani, D Palmerini, M Corezzi, G Mascherini, C Petri, R Klika, et al., Total Body Water Distribution in Breast Cancer Survivors Following Cancer Rehabilitation, J. Funct. Morphol. Kinesiol. 2 (2) (2017) 12.

[13] EB Haverkort, PLM Reijven, JM Binnekade, MAE de van der Schueren, CP Earthman, DJ Gouma, et al., Bioelectrical impedance analysis to estimate body composition in surgical and oncological patients: a systematic review, Eur. J. Clin. Nutr. 69 (1) (2015) 3-13.

[14] T Małecka-Massalska, A Smoleń, K Morshed, Extracellular-to-body cell mass ratio and subjective global assessment in head-and-neck cancers, Curr. Oncol. 21 (1) (2014) e62-e66.

[15] D Hui, J Moore, M Park, D Liu, E. Bruera, Phase angle and the diagnosis of impending death in patients with advanced cancer: preliminary findings, Oncologist 24 (6) (2019) e365-e373.

[16] LB. Sardinha, Physiology of exercise and phase angle: another look at BIA, Eur. J, Clin. Nutr. 72 (9) (2018) 1323-1327.

[17] C Earthman, D Traughber, J Dobratz, W. Howell, Bioimpedance spectroscopy for clinical assessment of fluid distribution and body cell mass, Nutr. Clin. Pract. 22 (4) (2007) 389-405.

[18] R Francisco, CN Matias, DA Santos, F Campa, CS Minderico, P Rocha, et al., The predictive role of raw bioelectrical impedance parameters in water compartments 
and fluid distribution assessed by dilution techniques in athletes, Int. J. Environ. Res. Public Health 17 (3) (2020) 759.

[19] E Marini, F Campa, R Buffa, S Stagi, CN Matias, S Toselli, et al., Phase angle and bioelectrical impedance vector analysis in the evaluation of body composition in athletes, Clin. Nutr. 39 (2) (2020) 447-454.

[20] F Campa, CN Matias, E Marini, SB Heymsfield, S Toselli, LB Sardinha, et al., Identifying athlete body fluid changes during a competitive season with bioelectrical impedance vector analysis, Int. J Sports Physiol. Perform. 15 (3) (2020) 361-367, 1 de Março de.

[21] K Norman, N Stobäus, D Zocher, A Bosy-Westphal, A Szramek, R Scheufele, et al., Cutoff percentiles of bioelectrical phase angle predict functionality, quality of life, and mortality in patients with cancer, Am. J. Clin. Nutr. 92 (3) (2010) 612-619.

[22] O Selberg, D. Selberg, Norms and correlates of bioimpedance phase angle in healthy human subjects, hospitalized patients, and patients with liver cirrhosis, Eur. J. Appl. Physiol. 86 (6) (2002) 509-516.

[23] UG Kyle, EP Soundar, L Genton, C. Pichard, Can phase angle determined by bioelectrical impedance analysis assess nutritional risk? A comparison between healthy and hospitalized subjects, Clin. Nutr. 31 (6) (2012) 875-881.

[24] A Davenport, RH Sayed, S. Fan, Is extracellular volume expansion of peritonea dialysis patients associated with greater urine output? Blood Purification 32 (3) (2011) 226-231.

[25] T Miura, Y Matsumoto, T Kawaguchi, Y Masuda, A Okizaki, H Koga, et al., Low Phase angle is correlated with worse general condition in patients with advanced cancer, Nutr. Cancer 71 (1) (2019) 83-88.

[26] A Brzozowska, R Mlak, P Gołębiowski, T. Małecka-Massalska, Status of hydration assessed by bioelectrical impedance analysis: a valuable predictive factor for radiation-induced oral mucositis in head and neck cancer patients, Clin. Transl. Oncol. 21 (5) (2019) 615-620.

[27] CN Matias, CP Monteiro, DA Santos, F Martins, AM Silva, MJ Laires, et al., Magnesium and phase angle: a prognostic tool for monitoring cellular integrity in judo athletes, Magnes. Res. 28 (3) (2015) 92-98.

[28] TLN Gomes, JDP Soares, TC Borges, C Pichard, GD Pimentel, Phase angle is not associated with fatigue in cancer patients: the hydration impact, Eur. J. Clin. Nutr. 74 (9) (2020) 1369-1373.

[29] WMA. World, Medical association declaration of helsinki: ethical principles for medical research involving human subjects, J. Am. Med. Assoc. 310 (20) (2013) 2191.

[30] M Marfell-Jones, T Olds, A Stewart, J. Carter, International Standards for Anthropometric Assessment, Lower Hutt, New Zealand, 2011.

[31] TG Lohman, AF Roche, R. Martorell, Anthropometric Standardization Reference Manual, Human Kinetics, Champaign, IL, 1988.

[32] EM Yang, E Park, YH Ahn, HJ Choi, HG Kang, HI Cheong, et al., Measurement of fluid status using bioimpedance methods in Korean pediatric patients on hemodialysis, J. Korean Med. Sci. 32 (11) (2017) 1828-1834.

[33] F Buckinx, J-Y Reginster, N Dardenne, J-L Croisiser, J-F Kaux, C Beaudart, et al. Concordance between muscle mass assessed by bioelectrical impedance analysis and by dual energy X-ray absorptiometry: a cross-sectional study, BMC Musculoskelet. Disord. 16 (1) (2015) 16-60.

[34] AM Silva, CN Matias, CL Nunes, DA Santos, E Marini, HC Lukaski, et al., Lack of agreement of in vivo raw bioimpedance measurements obtained from two single and multi-frequency bioelectrical impedance devices, Eur. J. Clin. Nutr. 73 (7) (2019) 1077-1083.

[35] SB Santagnello, FM Martins, GN de Oliveira Junior, J de Freitas Rodrigues de Sousa, RS Nomelini, EFC Murta, et al., Improvements in muscle strength, power, and size and self-reported fatigue as mediators of the effect of resistance exercise on physical performance breast cancer survivor women: a randomized controlled trial, Support Care Cancer 28 (12) (2020) 6075-6084.

[36] KM Winters-Stone, J Dobek, JA Bennett, LM Nail, MC Leo, A. Schwartz, The effect of resistance training on muscle strength and physical function in older, postmenopausal breast cancer survivors: a randomized controlled trial, J. Cancer Surviv. 6 (2) (2012) 189-199.

[37] R Rikli, J. Jones, Development and validation of a functional fitness test for community-residing older adults, J. Aging Phys. Act. 7 (2) (1999) 129-161, a.

[38] R Rikli, C. Jones, Functional fitness normative scores for community-residing older adults, ages 60-94, J. Aging Phys. Act. (7) (1999) 162-181, b.
[39] D Podsiadlo, S. Richardson, The timed "Up \& Go": a test of basic functional mobility for frail elderly persons, J. Am. Geriatr. Soc. 39 (2) (1991) 142-148.

[40] C Harris, AP Wattles, M Debeliso, PG Sevene-Adams, JM Berning, KJ. Adams, The seated medicine ball throw as a test of upper body power in older adults, J. Strength Cond. Res. 28 (8) (2011) 2344-2348.

[41] K Schmidt, L Vogt, C Thiel, E Jäger, W. Banzer, Validity of the six-minute walk test in cancer patients, Int. J. Sports Med. 34 (07) (2013) 631-636.

[42] RE Rikli, CJ. Jones, The reliability and validity of a 6-minute walk test as a measure of physical endurance in older adults, J. Aging Phys. Act. 6 (4) (1998) 363-375.

[43] WG Hopkins, SW Marshall, AM Batterham, J. Hanin, Progressive statistics for studies in sports medicine and exercise science, Med. Sci. Sports Exerc. 41 (1) (2009) 3-13.

[44] JW. Cohen, Statistical Power Analysis for the Behavioral Sciences, 2nd ed., Lawrence Erlbaum Associates, Hillsdale, 1988.

[45] MC Barbosa-Silva, AJ Barros, J Wang, SB Heymsfield, Pierson RNJr, Bioelectrical impedance analysis: population reference values for phase angle by age and sex1-3, Am. J. Clin. Nutr. 82 (1) (2005) 49-52.

[46] SL Yoon, O Grundmann, JJ Williams, L Gordan, TJ George, Body composition changes differ by gender in stomach, colorectal, and biliary cancer patients with cachexia: Results from a pilot study, Cancer Med. 7 (8) (2018) 3695-3703.

[47] D Hui, R Dev, L Pimental, M Park, MA Cerana, D Liu, et al., Association between multi-frequency phase angle and survival in patients with advanced cancer, J. Pain Symptom. Manage. 53 (3) (2017) 571-577.

[48] AP Pagano, JMF Sicchieri, IL Schiavoni, D Barbeiro, CS Manca, BR da Silva, et al., Phase angle as a severity indicator for liver diseases, Nutrition. 70 (2020), 110607.

[49] KH Cho, EY Han, SA Lee, H Park, C Lee, SH. Im, Feasibility of bioimpedance analysis to assess the outcome of complex decongestive therapy in cancer treatment-related lymphedema, Front. Oncol. 10 (2020) 111.

[50] M McManus, K Churchwell, K. Strange, Regulation of cell volume in health and disease, The N. Engl. J. Med. 19 (333) (1995) 1260-1266.

[51] K-H Schulz, S Patra, H Spielmann, S Klapdor, K Schlüter, S. van Eckert, Physical condition, nutritional status, fatigue, and quality of life in oncological out-patients, SAGE Open Med. 5 (2017), 2050312117743674.

[52] JY Lee, HS Ryu, SS Yoon, EH Kim, SW. Yoon, Extracellular-to-Intracellular Fluic Volume Ratio as a Prognostic Factor for Survival in Patients With Metastatic Cancer, Integr. Cancer Ther. 18 (2019), 153473541984728.

[53] K. Ellis, Human body composition: in vivo methods, Physiol. Rev. 2 (80) (2000) 649-680.

[54] MC Gonzalez, TG Barbosa-Silva, RM Bielemann, D Gallagher, SB. Heymsfield, Phase angle and its determinants in healthy subjects: influence of body composition, Am. J. Clin. Nutr. 103 (3) (2016) 712-716.

[55] Y Yamada, DA Schoeller, E Nakamura, T Morimoto, M Kimura, S. Oda, Extracellular water may mask actual muscle atrophy during aging, J. Gerontol. A Biol. Sci. Med. Sci. 65A (5) (2010) 510-516.

[56] L Stefani, N Maffulli, G Mascherini, L Francini, C Petri, G. Galanti, Exercise as prescription therapy: benefits in cancer and hypertensive patients, Transl. Med, UniSa. 11 (2014) 39-43.

[57] Reis Mafalda, Strength, Water Compartments and Phase Angle in Breast Cancer Survivors. [Mestrado], Universidade de Lisboa: Faculdade de Motricidade Humana, [Lisboa], 2016.

[58] K Norman, M Pirlich, J Sorensen, P Christensen, M Kemps, T Schütz, et al, Bioimpedance vector analysis as a measure of muscle function, Clin. Nutr. 28 (1) (2009) 78-82.

[59] AM Silva, DA Fields, SB Heymsfield, LB. Sardinha, Relationship between changes in total-body water and fluid distribution with maximal forearm strength in elite judo athletes, J. Strength Cond. Res. 25 (9) (2011) 2488-2495.

[60] KL Hsieh, TA Wood, R An, L Trinh, JJ Sosnoff, Gait and balance impairments in breast cancer survivors: a systematic review and meta-analysis of observational studies, Arch. Rehabil. Res. Clin. Transl. 1 (1-2) (2019), 100001.

[61] M Ali, M Moeller, L Rybicki, HCF. Moore, Long-term peripheral neuropathy symptoms in breast cancer survivors, Breast Cancer Res. Treat. 166 (2) (2017) $519-526$

[62] DA Galvão, DR Taaffe, N Spry, P Cormie, D Joseph, SK Chambers, et al., Exercise preserves physical function in prostate cancer patients with bone metastases, Med. Sci. Sports Exerc. 50 (3) (2018) 393-399. 